\title{
TORSION OF RIGHT UN-DESCENDED TESTIS; RIGHT INGUINAL ABSCESS
}

\author{
Dr. Muhammad Khalid
}

District Surgeon,

D.H.Q, Hospital,

Toba Tek Singh.

Correspondence Address:

Dr. Muhammad Khalid

District Surgeon,

D.H.Q, Hospital,

Toba Tek Singh.

Article received on:

23/01/2014

Accepted for Publication:

15/02/2014

Received after proof reading:

$21 / 04 / 2014$

\section{INTRODUCTION}

Inguinal Abscess due to torsion of a cryptorchid testicle is an uncommon condition. Testicular torsion is classically described as having a bimodal distribution with peaks being within the first year of life and early in puberty ${ }^{5}$. Although this bimodal distribution is the most common presentation. Torsion can occur at any age and must be considered in any male with acute inguinal, scrotal or abdominal pain ${ }^{6}$. Although a rare event overall, among patients with undescended testes, torsion is not uncommon and is the primary indication for surgical correction once the patient is deemed safe for general anesthesia. A recent 20-year retrospective review found only 11 cases with most cases in the perinatal period ${ }^{7}$. Another study found a torsion rate of $3.8 \%$ of patients going to the operating room with an undescended testis ${ }^{8}$. Andersen and Wille-Jorgensen ${ }^{9}$ present a $3.6 \%$ rate of undescended testicular torsion in a 5-year retrospective study of patients with suspected torsion. For poorly understood reasons, torsion more commonly occurs in the left testis ${ }^{10}$. The presentations of these cases have been associated with groin pain, a palpable mass or inconsolable crying. None of these cases are reported in the 1- to 3-year-old age range; most are in children under 1 year of age, making this a unique case in medical literature.

\section{CASE REPORT}

A 14 months old child was admitted in surgical unit of District Head Quarters Hospital Toba Tek Singh with history of pain and swelling of right inguinal region for the last seven days. Child's mother also told that he had loss of appetite and high grade fever. Physical exam revealed heart rate of 150 beats per minute, respiratory rate of 28 breaths per minute, temperature of $100.4^{\circ} \mathrm{F}$. The child was fussy. Local and genitourinary examination was performed, which revealed that his right inguinal region was swollen and fluctuant, that was $5 \mathrm{~cm}$ in greatest dimension.

Laboratory studies were remarkable for a leukocytosis of 15.7 and an elevated erythrocyte sedimentation rate $90 \mathrm{~mm}$ per hour. Blood sugar was $85 \mathrm{mgs} \%$ and urine studies were normal. An ultrasound examination of the inguinal area revealed an abscess with heterogeneous testicle, with no blood flow on Doppler examination. 
Incision and drainage confirmed torsion of the right undescended testis. After Incision and drainage and orchiectomy patient showed uneventful recovery.

\section{DISCUSSION}

Testicular torsion is classically described as having a bimodal distribution with peaks being within the first year of life and early in puberty ${ }^{5}$. Although this bimodal distribution is the most common presentation, torsion can occur at any age and must be considered in any male with acute inguinal, scrotal or abdominal pain ${ }^{6}$. Although a rare event overall, among patients with undescended testes, torsion is not uncommon and is the primary indication for surgical correction once the patient is deemed safe for general anesthesia. A recent 20-year retrospective review found only 11 cases with most cases in the perinatal period ${ }^{7}$. Another study found a torsion rate of $3.8 \%$ of patients going to the operating room with an undescended testis ${ }^{8}$. Andersen and Wille-Jorgensen ${ }^{9}$ present a $3.6 \%$ rate of undescended testicular torsion in a 5-year retrospective stiidy of patients with suspected torsion. For poorly understood reasons, torsion more commonly occurs in the left testis ${ }^{10}$. The presentations of these cases have been associated with groin pain, a palpable mass or inconsolable crying most are in children under 1 year of age, making this a tmique case in medical literature.

In the undescended testicle, torsion classically occurs in the perinatal period and is considered unlikely after the first year of life. However, the highest incidence of testicular torsion occurs in the young adult population ${ }^{11}$. Most testes are unsalvageable at the time of diagnosis due to the difficulty of the diagnosis in this age range $e^{6,7}$. Due to the consequences of a missed diagnosis, clinicians must have a high index of suspicion. Doppler ultrasound has emerged as the test of choice for diagnosis of testicular torsion; however, a high false negative rate remains. Sensitivity of $87.9 \%$ and specificity of $93.3 \%$ for Doppler ultrasound for testicular torsion is reported, but this is much lower in the case of the undescended testis $^{12,13}$. Current literature recommends orchiopexy by the age of 2 . The rate of spontaneous descent declines significantly after 3 months of age, and the risks of surgery and general anesthesia decrease after 1 year $^{14}$. The previous cases reported in the literature of infants or toddlers with undescended testicular torsion had symptoms that led to a diagnosis of nonspecific abdominal pain leading to the fmal diagnosis.

Testicular torsion must be included in the differential of any child with an empty scrotimi and concerning symptoms. Salvage rates are estimated at $90 \%$ to $100 \%$ if detorsion occurs within 6 hours of onset of symptoms, but decline to $20 \%$ after 12 hours and $0 \%$ to $10 \%$ if delayed longer than 24 hours $^{16}$. However, severe damage is reported to occur within 4 hours of onset of symptoms $^{17}$. Early surgical consultation is critical, even prior to definitive diagnosis if suspicion is high enough.

\section{CONCLUSIONS}

The primary issues in the case of a pediatric patient with an undescended testicular torsion are both delay in presentation and delay in diagnosis, leading to a necrotic testicle. These children usually present late with nonspecific symptoms that lead to a broad differential that must be quickly narrowed if the child is to have a salvageable testicle. Patients undergoing orchiectomy can have issues with fertility later in life secondary to a decreased sperm count. This case demonstrates a nonspecific history and physical examination in a child outside the classic age range for testicular torsion. Emergency physicians must use available diagnostic tools to quickly narrow the differential and appropriately dispose the child to raise the chance of a salvageable testicle.

Copyright@ 15 Feb, 2014.

\section{REFERENCES}

1. Leet $\mathrm{Al}$, Skaggs $\mathrm{DL}$. Evaluation of the acutely limping child. Am Fam Physician. 2000; 61:10111018. [PubMed]

2. Kocher MS, Mandiga R, Murphy JM, et al. A clinical practice guideline for treatment of septic arthritis 
in children: efficacy in improving process of care and effect on outcome of septic arthritis of the hip. J Bone Joint Surg Am. 2003;;85-A:994-999, [PubMed].

3. McCullough $M$, Sharieff GQ. Abdominal pain in children. Pediair Clin North Am. 2006;;53:107-137. [PubMed]

4. $\quad$ De Boeck $\mathrm{H}$, Vorlat P. Limping in childhood. Acta Orthop Belg. 2003;; 69:301-310. [PubMed]

5. Cuckow PM, Frank JD. Torsion of the testis. BJU Int. 2000;; 86:349-353. [PubMed]

6. Saad S, Duckett 0. Urologic and gynecologic problems in children. In: Tintinalli JE, Ruiz E, Krome RL, editors. Emergency Medicine: A Comprehensive Study Guide. 6th ed. New York, NY: McGraw-Hill;;2004. pp. 900-905.

7. Zilbeiroan D, Inbar Y, Hcyman Z, et al. Torsion of the cryptorchid testis-can it be salvaged? J f/ro/. 2006;; 175:2287-2289. [PubMed].

8. Ibrahim AH, Al-Malki TA, Ghali AM, et al. Undescended testes: Do we need to fix them earlier? Ann Pediatr Surg. 2005;;1:21-25.

9. Andersen L, Wille-Jorgensen PA. Torsion of the testis. A 5-year material. ScandJ Urol Nephrol. 1990;;24:91-93. [PubMed].
10. Ringdahl E, league L. Testicular torsion. Am Fam Physician. 2006;; 74:1739-1743. [PubMed]

11. Mowad JJ, Konvolinka CW. Torsion of undescended testis. Urology. 1978;; 12:567-568. [PubMed]

12. Liu CC, Huang SP, Chou $\mathrm{YH}$, et al. Clinical presentation of acute scrotum in young males. KaohsiungJ Med Sci. 2007;; 23:281-286, [PubMed].

13. Bentley DF, Ricchiuti DJ, Nasrallah PF, et al. Spermatic cord torsion with preserved testis perfusion: initial anatomical observations. J Urol. 2004;; 172:2373-2376, [PubMed].

14. Barthold JS, Gonzalez R. The epidemiology of congenital cryptorchidism, testicular ascent and orchiopexy. J Urol. 2003;; 170:2396-2401. [PubMed].

15. Singh KA. Gabriel K. Pediatric musculoskeletal complaints. In: Daniels J, Hoffman MR, editors. Common Musculoskeletal Problems: A Handbook. New Yorit, NY: Springer;; 2010. pp. 79-88,

16. Cattolica EV, Karol JB, Rankin KN, et al. High testicular salvage rate in torsion of the spermatic cord, JUrol. 1982;; 128:66-68, [PubMed]

17. Candocia FJ. Sack-Solomon K, An infant with testicular torsion in the inguinal canal. Pediatr Radiol. 2003;; 33:722-724. [PubMed].

\section{Do not spoil what you have by desiring what you have not; remember that what you now have was once among the things you only hoped for.}

